\title{
Efficiency of Scintillator Materials in the Energy Range 8.0-32.0 keV
}

\author{
J.H. Kinney, D.L. Haupt
}

July 1, 2002

U.S. Department of Energy

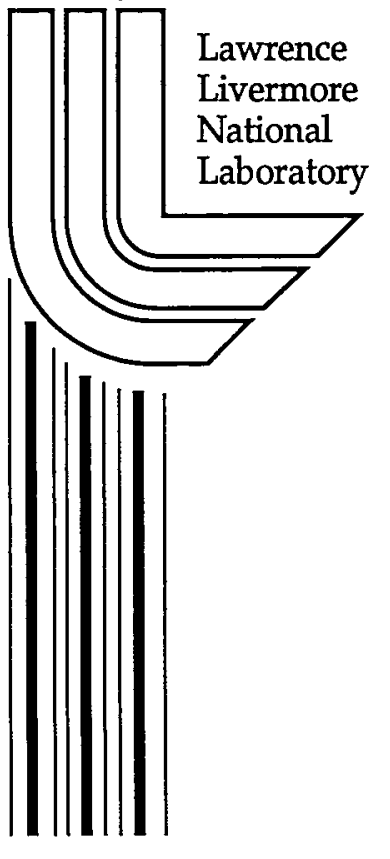




\section{DISCLAIMER}

This document was prepared as an account of work sponsored by an agency of the United States Government. Neither the United States Government nor the University of California nor any of their employees, makes any warranty, express or implied, or assumes any legal liability or responsibility for the accuracy, completeness, or usefulness of any information, apparatus, product, or process disclosed, or represents that its use would not infringe privately owned rights. Reference herein to any specific commercial product, process, or service by trade name, trademark, manufacturer, or otherwise, does not necessarily constitute or imply its endorsement, recommendation, or favoring by the United States Government or the University of California. The views and opinions of authors expressed herein do not necessarily state or reflect those of the United States Government or the University of California, and shall not be used for advertising or product endorsement purposes.

This work was performed under the auspices of the U.S. Department of Energy by the University of California, Lawrence Livermore National Laboratory under Contract No. W-7405-Eng-48.

This report has been reproduced directly from the best available copy.

Available electronically at http://www.doc.gov/bridge

Available for a processing fee to U.S. Department of Energy

And its contractors in paper from

U.S. Department of Energy

Office of Scientific and Technical Information

P.O. Box 62

Oak Ridge, TN 37831-0062

Telephone: (865) 576-8401

Facsimile: (865) 576-5728

E-mail: reports@adonis.osti.gov

Available for the sale to the public from

U.S. Department of Commerce

National Technical Information Service

5285 Port Royal Road

Springfield, VA 22161

Telephone: (800) 553-6847

Facsimile: (703) 605-6900

E-mail: orders@ntis.fedworld.gov

Online ordering: http://www.ntis.gov/ordering.htm

OR

Lawrence Livermore National Laboratory

Technical Information Department's Digital Library

http://www.llnl.gov/tid/Library.html 
Efficiency of Scintillator Materials in the Energy Range 8.0-32.0 keV

\author{
J.H. Kinney and D.L. Haupt \\ Department of Mechanical Engineering \\ Lawrence Livermore National Laboratory \\ Livermore, CA
}

Corresponding author:

J.H. Kinney

L-333

(925)-422-6669

kinney3@llnl.gov 


\section{Introduction}

$\mathrm{X}$-ray microtomography requires the measurement of $\mathrm{x}$-ray attenuation along ray paths through a specimen, and on the inversion of these data to obtain a spatially resolved mapping of the microstructure of the specimen. To do this efficiently, two-dimensional array detectors are often used to measure the transmitted x-rays by capturing and recording each $\mathrm{x}$-ray incident on the detector. The highest resolution $\mathrm{CT}$ instruments perform this by converting the incident x-rays to visible light, and then focusing this light onto a charge-coupled-device (CCD) detector. The light output of the scintillator (photons per incident $\mathrm{X}$-ray), the numerical aperture of the optical lens system, and the quantum efficiency of the CCD govern the efficiency of the detection process.

Several years earlier, our group performed an investigation aimed at determining the best scintillator material for high-resolution synchrotron CT. The selection criteria included light output in the 8-32 $\mathrm{keV}$ energy range, the spatial resolution of the scintillator, the wavelength of the scintillation radiation, and the stability and ease of polishing of the scintillator. A list of the scintillators that we considered, with the exceptions of the more recently developed glass scintillators, is provided in Table 1. Among these scintillators, we concluded that single crystal cadmium tungstate was optimum; we have used this material in all subsequent synchrotron CT systems.

Since this original study, several doped-glass scintillators have become available. The LSO (Lu orthosilicates) scintilators, developed for PET scanning, show considerable light output at high energy (energies above $500 \mathrm{keV}$ ). Theoretically, the light output of these scintillators should be twice that of the cadmium tungstate. The purpose of this study was to determine the efficiency of two such scintillators (LSO:Yt and IQI-401 high density terbium activated glass) in the energy range from $8-32 \mathrm{keV}$.

Table 1: Properties of some known scintillator materials

\begin{tabular}{|c|c|c|c|c|c|c|}
\hline $\begin{array}{l}\text { Common } \\
\text { Name }\end{array}$ & $\begin{array}{l}\text { Chemical } \\
\text { Formula }\end{array}$ & $\begin{array}{c}\text { Light Output } \\
\text { (photons/MeV) }\end{array}$ & $\begin{array}{c}\text { Peak } \\
\text { Wavelength } \\
\text { (nm) }\end{array}$ & $\begin{array}{c}\text { Density } \\
\text { g/cm }\end{array}$ & $\begin{array}{c}\text { Decay } \\
\text { Constant } \\
(\mu s)\end{array}$ & Stability \\
\hline $\begin{array}{l}\text { cadmium } \\
\text { tungstate }\end{array}$ & $\mathrm{CdWO}_{4}$ & 13,000 & 520 & 7.90 & 20.0 & stable \\
\hline BGO & $\mathrm{Bi}_{4} \mathrm{Ge}_{3} \mathrm{O}_{12}$ & 8,500 & 480 & 7.13 & 0.30 & stable \\
\hline LSO & $\mathrm{Lu}_{2} \mathrm{SiO}_{5}: \mathrm{Ce}$ & 30,000 & 415 & 7.40 & 0.04 & stable \\
\hline $\begin{array}{l}\text { sodium } \\
\text { iodide }\end{array}$ & $\mathrm{NaI}$ & $?$ & 300 & 3.70 & 0.23 & hygroscopic \\
\hline $\begin{array}{l}\text { cesium } \\
\text { iodide }\end{array}$ & CsI & 16,800 & 310 & 4.51 & $0.03-0.1$ & deliquescent \\
\hline IQI-401 & $?$ & $?$ & 543 & 3.50 & 3400 & stable \\
\hline
\end{tabular}

Table 2: Quantum efficiency of the KAF-63003E CCD at various wavelengths.

\begin{tabular}{rccc}
\hline wavelength (nm) & $\mathbf{4 5 0}$ & $\mathbf{5 5 0}$ & $\mathbf{6 5 0}$ \\
\hline quantum efficiency & $40 \%$ & $52 \%$ & $65 \%$ \\
\hline
\end{tabular}




\section{Materials and Methods}

The experimental apparatus is shown schematically in Figure 1. Synchrotron $\mathrm{x}-$ rays from the 15-period wiggler beamline 10-2 at Stanford Synchrotron Radiation Laboratory were used in the study. Monochromatic $x$-rays were obtained by using a double-crystal silicon monochromator; wavelength was tuned by varying the Bragg angle of the crystals. Energies of 8, 16, 24, and $32 \mathrm{keV}$ were selected for this study. X-ray flux incident on each scintillator was measured with a nitrogen-filled ion chamber.

Each scintillator was placed in the focal plane of the optical lens system, and the signal was imaged on a Kodak KAF 63003E CCD imaging sensor. The CCD was thermoelectrically cooled to $-35 \mathrm{C}$. The integration times were all less than 1 second; the pixel elements were filled to about 0.8 of the full well capacity. Scintillator efficiency was measured as the total number of electrons in the CCD per X-ray photon incident on the scintillator. All scintillators were polished; three cadmium tungstate, one BGO, and one LSO:Yt were imaged. In addition, two aluminized scintillators were also imaged: a cadmium tungstate control and the NDE special glass (IQI-401, Industrial Quality Inc, Gaithersburg, MD).

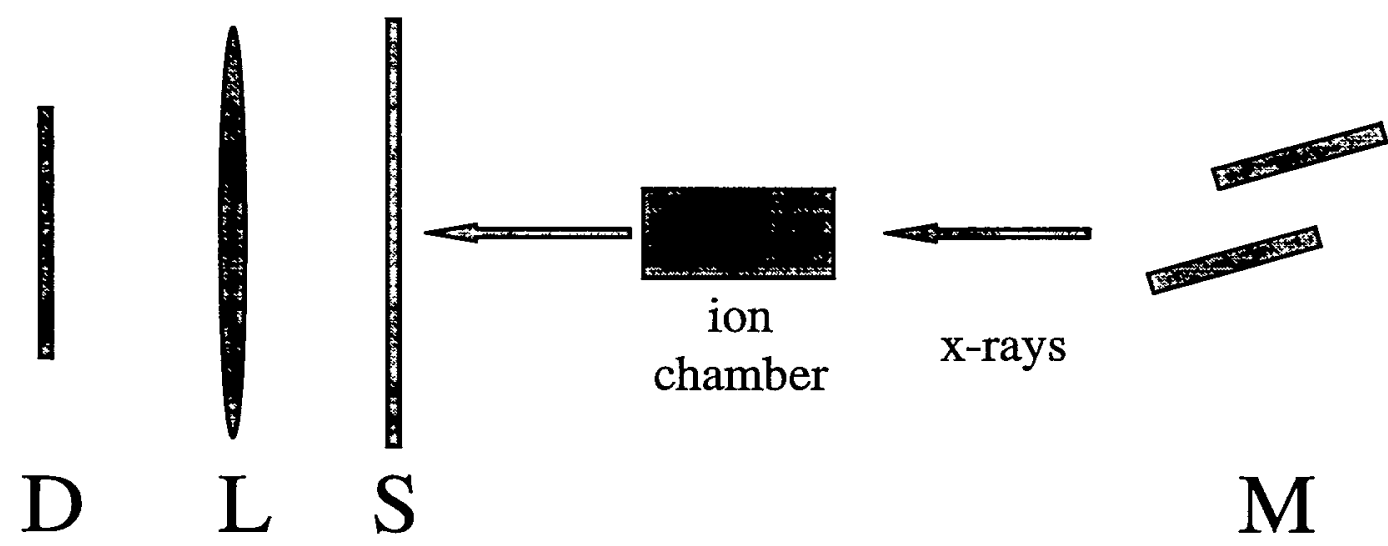

Figure 1: Schematic of the experimental setup. X-rays from the synchrotron source were made monochromatic by reflecting from two single crystals of silicon cut in the (220) plane. The energy was selected by varying the Bragg angle. The x-ray flux incident on the scintillator was measured with an ion chamber. The $x$-rays were captured in the scintillator; the visible light output was then imaged with the $0.77 \mathrm{X}$ lens onto a Kodak KAF 6303E CCD image sensor. 


\section{Results}

The results are graphically summarized in Figures 2-5. At all energies, the cadmium tungstate was the most efficient scintillator.

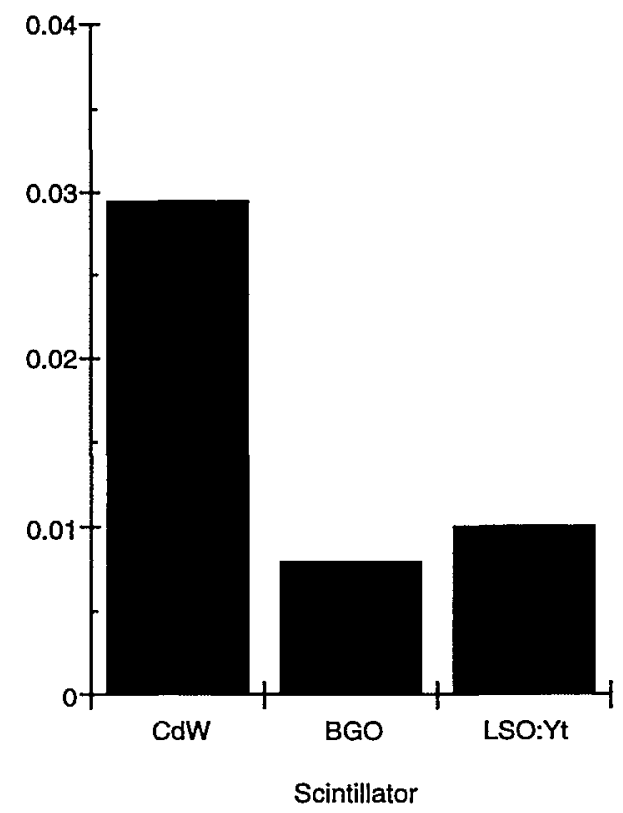

Figure 2: Light output (electrons per incident x-ray photon) of three scintillator materials at $8 \mathrm{keV}$. The cadmium tungstate $(\mathrm{CdW})$ is nearly three-times more efficient than the orthosilicate glass at this energy.

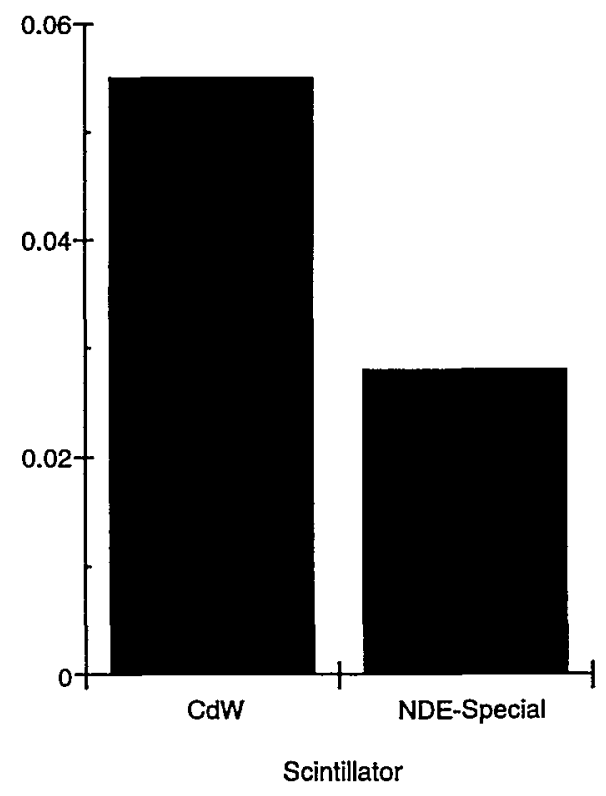

Figure 3: Light output of aluminized scintillators at $8 \mathrm{keV}$. At this energy, the aluminized cadmium tungstate (CdW) is more than twice as efficient as the NDESpecial Glass. 


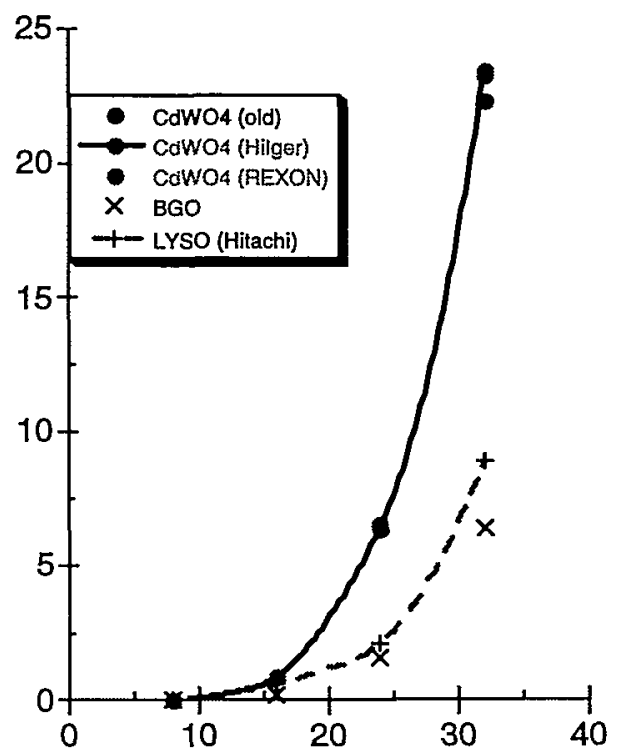

Energy (keV)

Figure 4: Light output (electrons per incident photon) of various scintillators as a function of $x$-ray energy from $8-32 \mathrm{keV}$. The three cadmium tungstate scintdillators were statistically identical, regardless of manufacturer. The BGO and LSO:Yt scintillators were less efficient at all energies studied.

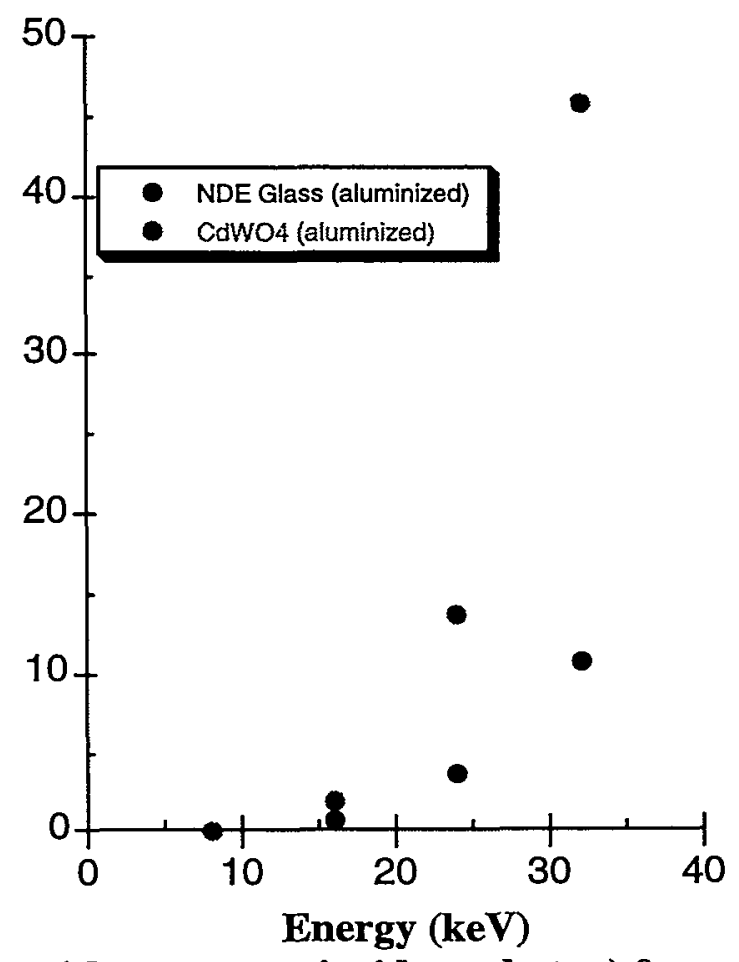

Figure 5: Light output (electrons per incident photon) from the aluminized scintillators over x-ray energies from 8-32 keV. NDE Glass was the IQI-401 glass listed in Table 1. 
Table 3: Light output of various scintillator materials (electrons/photon) at different x-ray energies.

\begin{tabular}{|r|cccc|}
\hline Scintillator & \multicolumn{4}{c|}{ Energy (keV) } \\
\hline & 8 & 16 & 24 & 32 \\
\cline { 2 - 5 } CdWO $_{4}$ & 0.03 & 0.88 & 6.35 & 22.33 \\
$\mathrm{BGO}$ & $<0.01$ & 0.22 & 1.56 & 6.38 \\
$\mathrm{IQI}-401^{*}$ & 0.03 & 0.71 & 3.76 & 10.74 \\
$\mathrm{LSO}$ & 0.01 & 0.63 & 2.08 & 8.87 \\
\hline
\end{tabular}

* aluminized

\section{Conclusions}

At $\mathrm{x}$-ray energies below $35 \mathrm{keV}$, cadmium tungstate remains the most efficient scintillator. Light output is enhanced about two-fold when the front surface is aluminized; it remains to be seen if the aluminized layer affects the spatial resolution of the scintillator. 